\title{
Identification of Enabling Factors for Collaboration in Management of Risk in Construction Projects: A Literature Review
}

\author{
1. Eng. Philemon, Z. Msomba; \\ Doctoral Student, \\ Department of Structural and Construction Engineering, \\ College of Engineering and Technology (COET), University of \\ Dar es salaam, Tanzania
}

\author{
2. Dr. Samson Matiko \\ Lecturer, \\ Department of Structural and Construction Engineering, \\ College of Engineering and Technology (COET), University of \\ Dar es Salaam, Tanzania
}

\author{
${ }^{3}$ Dr. Ramadhan, S. Mlinga \\ Lecturer, \\ Department of Structural and Construction Engineering, \\ College of Engineering and Technology (COET), \\ University of Dar es Salaam, Tanzania
}

\begin{abstract}
The increasing complexity, uncertainty and competition in construction industry have necessitated new approaches to managing project risks. In particular it has resulted into the development of collaborative approaches and diverse relationships among project participants. This paper critically reviews literature to identify key enabling factors for collaboration in management of risk in construction projects. The review identified fourteen factors which can be considered critical for collaboration within construction projects. Trust, open communication, commitment, fairly drafted contract, good relationship, skills/competence, information sharing, knowledge sharing, no-blame culture, mutual understanding, flexibility, seamless operation; proactive problem solving and fair distribution of responsibility are the most important enabling factors for collaboration.
\end{abstract}

Keywords: Construction projects, factors for collaboration, risk management

\subsection{INTRODUCTION}

Risks and uncertainty in construction projects increase with complexity of projects. Therefore, as projects increasingly become complex and big in size, new more effective approaches are sought to manage risks and uncertainty. One such approach, that is increasingly advocated for in the construction industry is collaborative risk management. Effective collaboration between the client, design team and contractor has been shown to enhance risk and uncertainty management through improving the dynamic capabilities of project participants (Davies et al, 2016). This approach was first advocated in the 1990s (Faulkner and De Rond, 2000). Throughout the academic literature, there are countless definitions of collaboration, as well as various opinions on what are the factors which could enable collaboration to be successful. This research presents a review of literature on enabling factors for collaboration in management of risks in construction projects. The objective of this review is to identify the factors considered by most authors to be critical to enabling collaboration among project key players. These factors are expected to form a basis and framework for enhancing joint risk management in construction projects and hence improve project performances.

Early literature on collaborative approaches in construction and project management were published in 1990s (Latham, 1994; Mayer et al., 1995; Bennet and Jayes, 1995; Love et al., 1998; Zaheer and McEvily, 1998; and Chua et al., 1999). This paper, although fundamentally reviews the factors enabling collaboration among project participants, it also evaluates the growth made in this young approach in construction risk management.

\subsection{COLLABORATIVE RISK MANAGEMENT PHILOSOPHY}

Collaboration is identified as a process in which entities share information, resources and responsibilities to jointly plan, implement, and evaluate a program of activities to achieve a common goal (Davies et al, 2016). It is a process of shared creation that involves mutual engagement of participants to solve a problem together and implies sharing risks, resources, responsibilities, and rewards. Sharing risks, resources, responsibilities, and rewards can also give the group to an outside observer the image of a joint identity. Real collaboration cannot happen without trust amongst the project team members.

In traditional project risk management construction parties (clients, consultants and contractors) have usually done so separately and in isolation (Sanchez-Cazorla et al, 2016). Collaborative risk management approach adds a new dimension to traditional risk management methods. Collaborative risk management provides approaches by which uncertainty can be understood, assessed, and managed within projects (Ashkenas, 2012). A collaborative approach to risk management integrates individual perspectives into a coherent and rounded risk management strategy, ultimately benefiting the project and all those concerned with it (Cattie and van Riper, 2012). The benefits of collaboration in management of risk include reduced project cost for the owner, higher profit 
for contractors, earlier completion of project and fewer contract disputes.

\subsection{METHODOLOGY}

The research method in this study is focuses on literature review from past research. Sources such as journal articles, books, international conference papers, and materials available on the Internet have been used as literature review in this study. While the literature search and review are not exhaustive, a systematic methodology was employed. In conducting search key terms/ phrases were used "collaboration in risk management"; "enabling factors for collaboration"; "team working" and collaboration of project participants in construction projects. Subsequently, inclusions of these search terms are applied to screen actual relevance of articles. Relevant articles are included based on how their titles, abstracts, and keywords addressing collaboration in risk management, team working in construction projects, enabling factors for collaboration and collaboration of project participants in construction projects. The literature search, based on key terms explained, contributed 45 relevant peerreviewed articles. However, additional articles and resources were also included by the authors from their current areas of focus (e.g. lean construction). In selecting key enabling factors for collaboration was based on their appearance frequencies in reviewed articles. Enabling factor appears in three or more articles is considered key factor for collaboration.

\subsection{LITERATURE REVIEW ABOUT COLLABORATIVE RISK MANAGEMENT}

The nature of the complexity and dynamic environments within the construction industry has led to the increasing need for the collaboration of all key players in any construction project in risk management in a multi-disciplinary team at both project management and design implementation levels (Evbuomwana and Anumbab, 1998). Based on the report by Leverick and Littler (1993), the demand for collaboration has moved from commercial pressures to an increase in complex projects, higher demand of innovation projects and technological development, and the higher demand in internationalization of the industries (Akintoye and Main, 2007). Stiles (1995) identified that the factors influencing collaboration around the world include: globalization demand, competition, risk and uncertainty within the business environment; while businesses as diverse as insurance, construction, airlines and computers are recognizing the need to collaborate in order to survive. Effective collaboration between the client, design team and contractor has been shown to enhance addressing risk and uncertainty through improving the dynamic capabilities of project participants (Davies et al, 2016). In general, collaboration and teamwork studies in construction have looked into various factors that enable collaboration between project team members, such as trust, team flexibility and seamless operation (Ibrahim et al, 2011; Adetola et al 2011), team leadership (Cheung et al, 2001), communication and no blame culture (Moore and Dainty, 1999), project team communication (Perry and Sanderson, 1998), project members' participation (Leung et al, 2004), Interdependence and Appropriate team composition (Tarricone and Luca, 2002). However, the key factors that contribute to effective collaboration are problem solving and decision making (Guzzo and Salas, 1995). Based on the literature reviewed above, a total of twenty [24] factors are identified and [14] were identified as critical to enabling collaboration among project participants in risk management, these are presented in Table 1 to Table 3 below, and further the adopted factors are explained in the proceeding.

Table 1 Enabling Factors for collaboration in management of risk from some of reviewed articles

\begin{tabular}{|c|c|c|c|c|c|c|c|c|}
\hline \multirow[b]{2}{*}{ Authors } & \multicolumn{8}{|c|}{ Proposed enabling factors } \\
\hline & $\stackrel{\overrightarrow{0}}{E}$ & 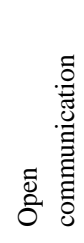 & 节 & 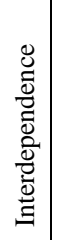 & 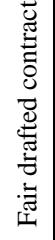 & 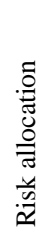 & 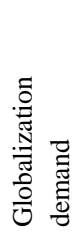 & 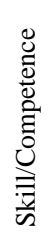 \\
\hline Adetola et al 2011 & $\sqrt{ }$ & $\sqrt{ }$ & & & & $\sqrt{ }$ & $\sqrt{ }$ & $\sqrt{ }$ \\
\hline 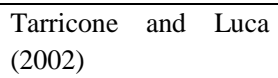 & & $\sqrt{ }$ & $\sqrt{ }$ & $\sqrt{ }$ & & & & $\sqrt{ }$ \\
\hline $\begin{array}{l}\text { Moore and Dainty } \\
(1999)\end{array}$ & & $\sqrt{ }$ & & & & $\sqrt{ }$ & & $\sqrt{ }$ \\
\hline Baiden et al. (2006) & $\sqrt{ }$ & $\sqrt{ }$ & $\sqrt{ }$ & & $\sqrt{ }$ & & & \\
\hline Love et al. (1998) & & $\sqrt{ }$ & & & & & & \\
\hline $\begin{array}{l}\text { Cicmil and Marshall } \\
(2005)\end{array}$ & $\sqrt{ }$ & $\sqrt{ }$ & $\sqrt{ }$ & & $\sqrt{ }$ & & & $\sqrt{ }$ \\
\hline $\begin{array}{lll}\text { Guzzo and } & \text { Salas } \\
(1995) & & \\
\end{array}$ & $\sqrt{ }$ & & & & & & & \\
\hline Leung at el (2004) & $\sqrt{ }$ & & & & & & & \\
\hline Stiles (1995) & & & & & $\sqrt{ }$ & & $\sqrt{ }$ & \\
\hline Ibrahim at el (2011) & $\sqrt{ }$ & $\sqrt{ }$ & $\sqrt{ }$ & & & & & \\
\hline $\begin{array}{l}\text { Factors adopted in this } \\
\text { study }\end{array}$ & $\sqrt{ }$ & $\sqrt{ }$ & $\sqrt{ }$ & & $\sqrt{ }$ & & & $\sqrt{ }$ \\
\hline
\end{tabular}

Table 2 Enabling Factors for collaboration in management of risk from some of reviewed articles

\begin{tabular}{|c|c|c|c|c|c|c|c|c|c|}
\hline \multirow[b]{2}{*}{ Authors } & \multicolumn{9}{|c|}{ Proposed enabling factors } \\
\hline & 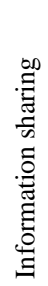 & 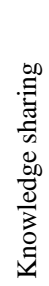 & $\underset{\text { 导 }}{\stackrel{Ð}{\Xi}}$ & 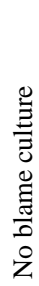 & 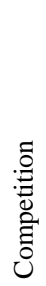 & 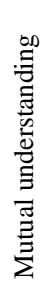 & 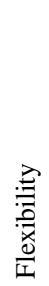 & 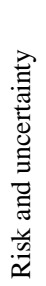 & 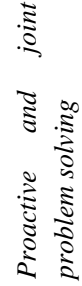 \\
\hline Adetola et al 2011 & & & $\sqrt{ }$ & & & $\sqrt{ }$ & & & \\
\hline $\begin{array}{l}\text { Tarricone and Luca } \\
(2002)\end{array}$ & & & & & & $\sqrt{ }$ & & & \\
\hline $\begin{array}{l}\text { Moore and Dainty } \\
(1999)\end{array}$ & & & & $\sqrt{ }$ & & & & & \\
\hline Baiden et al. (2006) & $\sqrt{ }$ & & & $\sqrt{ }$ & & & $\sqrt{ }$ & & \\
\hline Love et al. (1998) & & & & & & $\sqrt{ }$ & $\sqrt{ }$ & $\sqrt{ }$ & $\sqrt{ }$ \\
\hline $\begin{array}{l}\text { Cicmil and Marshall } \\
(2005)\end{array}$ & $\sqrt{ }$ & $\sqrt{ }$ & & & & & & & \\
\hline $\begin{array}{lll}\text { Guzzo and } & \text { Salas } \\
(1995) & & \\
\end{array}$ & & & & & & & & & $\sqrt{ }$ \\
\hline Leung at el (2004) & & $\sqrt{ }$ & & & & & $\sqrt{ }$ & & $\sqrt{ }$ \\
\hline Stiles (1995) & & & & & $\sqrt{ }$ & & & $\sqrt{ }$ & \\
\hline Ibrahim at el (2011) & $\sqrt{ }$ & & & $\sqrt{ }$ & & $\sqrt{ }$ & & & \\
\hline $\begin{array}{l}\text { Factors adopted in this } \\
\text { study }\end{array}$ & $\sqrt{ }$ & $\sqrt{ }$ & & $\sqrt{ }$ & & $\sqrt{ }$ & $\sqrt{ }$ & & $\sqrt{ }$ \\
\hline
\end{tabular}


Table 3 Enabling Factors for collaboration in management of risk from some of reviewed articles

\begin{tabular}{|c|c|c|c|c|c|c|c|}
\hline \multirow[b]{2}{*}{ Authors } & \multicolumn{7}{|c|}{ Proposed enabling factors } \\
\hline & 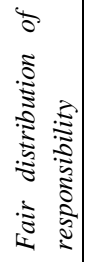 & 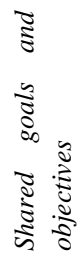 & 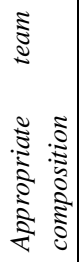 & 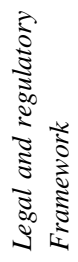 & 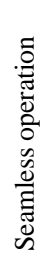 & 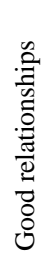 & 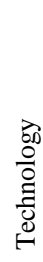 \\
\hline Adetola et al 2011 & & $\sqrt{ }$ & $\sqrt{ }$ & $\sqrt{ }$ & $\sqrt{ }$ & $\sqrt{ }$ & $\sqrt{ }$ \\
\hline $\begin{array}{l}\text { Tarricone and Luca } \\
(2002)\end{array}$ & & $\sqrt{ }$ & $\sqrt{ }$ & $\sqrt{ }$ & & & \\
\hline $\begin{array}{l}\text { Moore and Dainty } \\
(1999)\end{array}$ & & & & & & $\sqrt{ }$ & \\
\hline Baiden et al. (2006) & $\sqrt{ }$ & & & & $\sqrt{ }$ & $\sqrt{ }$ & $\sqrt{ }$ \\
\hline \multicolumn{8}{|l|}{ Love et al. (1998) } \\
\hline \multicolumn{8}{|l|}{$\begin{array}{l}\text { Cicmil and Marshall } \\
(2005)\end{array}$} \\
\hline $\begin{array}{l}\text { Guzzo and Salas } \\
(1995)\end{array}$ & & & & & $\sqrt{ }$ & & $\sqrt{ }$ \\
\hline Leung at el (2004) & $\sqrt{ }$ & & & & & & \\
\hline \multicolumn{8}{|l|}{ Stiles (1995) } \\
\hline Ibrahim at el (2011) & $\sqrt{ }$ & & & & $\sqrt{ }$ & & \\
\hline $\begin{array}{l}\text { Factors adopted in this } \\
\text { study }\end{array}$ & $\sqrt{ }$ & & & & $\sqrt{ }$ & $\sqrt{ }$ & \\
\hline
\end{tabular}

\subsection{DISCUSSIONS}

This section synthesizes and subsequently presents detailed discussions on identified enabling factors for collaboration in management of risks in construction projects.

\subsection{Trust among participants}

Trust is an aspect of relationships described as a firm belief, confidence and hope in the reliability, truth, ability or strength of someone or something (Bennett and Jayes, 1995). Rousseau et al, (1998) defined trust as a psychological state comprising the intention to accept vulnerability based upon positive expectations of the intentions or optimize of another. Trust impacts decision making because decisions are made in light of the level of trust and the perceived risk; moreover such decisions are also referred as risk taking in relationship (RTR) (Mayer et al., 1995). Collaboration requires trust at its core. Risk is another prerequisite of trust. If there were complete certainty and the absence of risks in a relationship, trust would be unnecessary (Lewis and Weigert, 1985; Jin and Ling, 2005). More trust would need to be fostered when more risks exist. Trust is encouraged to counterbalance these risks. Zaheer et al. (1998) found that "firms in exchange relationships may derive competitive advantage from relationships imbued with high levels of inter-organizational trust". Dirks (1999) found trust to have a positive influence, albeit indirect, on group performance.

Trust is a dynamic phenomenon since it could develop, decline, be built or resurface in long standing relationships within organisations. Lack of trust and commitment are important factors that can deter the development of collaboration and integrated teams (Rahman and Kumaraswamy, 2008). One of the most fundamental differences in the collaborative approach is the requirement to trust other team members and recognise that they are trying to achieve the very best results of which they are capable (SFC, 2003). In order to achieve collaboration among the entire project team and particularly towards managing project risks, trust is critical (Moore and Dainty, 2001, Cicmil and Marshall, 2005).

\subsection{Open Communication about every aspect of the project}

Communication has by many researchers been found to be a critical success factor in project management for collaborations' readiness of risk management (Pritchard, 2004; Yaraghi and Langhe, 2011). Kerzner, (1995) claim that communication plays an important role in risk mitigation. Intuitively and as confirmed in the literature, communication is a prerequisite for successful project management and collaboration in risk management to align. The communication in projects with multiple stakeholders, such as construction projects, is however more difficult to manage. Effective communication may help to coordinate work activities, manage information/knowledge and make decision. As described by Love et al. (1998), communication has been linked to team effectiveness, the integration of work units across organisational levels, characteristics of effective supervision, job satisfaction, and overall organisational effectiveness.

Effective collaboration in risk management often relies on clear communications and the ability to pass thoughts, ideas, information and instructions quickly and effectively between people with different technical skills and interest. By establishing communication flows, involvement patterns and other behavioural responses to unexpected change events, the nature of any professional and cultural interfaces can be established (Moore and Dainty, 2001). Evbuomwan and Anumba (1998) found that lack of communication between all key players in any construction project in a multi-disciplinary team has led to difficulty in the development process for both project management and design implementation levels.

As previous researchers have proved, project communication is frequently mentioned as a key success factor (Kerzner, 1995; Pritchard, 2004), but can be difficult in many cases where the project involves graphically distributed stakeholders, meaning that regular meetings and communication between the steering group and the project group might be difficult to arrange. Communication between project participants can be either internal or external, formal or informal, vertical or horizontal, official or unofficial (PMI, 2013). Communication between the different parties is essential for collaboration when one considers the different responsibilities of the parties associated with a project. The effectiveness of parties' collaboration is a function of the effectiveness of the communication between the various parties (Engelbrecht, 2010).

\subsection{Commitment of each and all project participants}

Commitment enhances collaboration in handling risks because it helps the project team members to remain focused on the project goals and, consequently to find creative solutions, using the available resources and current knowledge, to reach those goals. The literature refers to this attitude as goal commitment and, it is defined as the personal 
determination to try for a goal or keep trying for a goal (MeiYung et al., 2004). In agreement with Fowler and Horan (2007), the review findings revelled that a combination of project team commitment and top management commitment is necessary to achieve the desirable project outcomes.

Commitment and support from top management is important in every kind of management and it is thus an important factor for collaborative risk management. Ochieng and Price (2009) identified commitment from senior / top management as a key indicator of team collaboration practice, as it is critical to success in multicultural team environments. The importance of top management support towards collaboration in management of risks has been supported by these scholars (Kleffner et al., 2003). The top management support is also required, especially towards effective provision of resources, structure and creation of a collaborative risk management culture which enhances implementation. The issue of commitment is of central importance to collaboration, as construction projects involve complex organisational and technically challenging design/construction systems.

\subsection{Fair drafted contract}

Contracts fundamentally describe obligations responsibilities and allocate risks to the parties (Soetanto, 2002). According to Klemetti (2006), contracts normally act as instruments for sharing risks, though researchers tend to think that in the construction industry exhaustive risk allocation cannot be achieved solely through contractual arrangements. The form and clarity of contracts, the quality of documentation, and the method of payment have significant impacts on performance. Ambiguous and inappropriate contracts that allocate risks unfairly, lead to disputes and conflicts. The consequence of all this is to detract some members from the pursuit of project goals resulting in poor performance (Wiguna and Scott, 2006). According to Chua et al. (1999) a fairly drafted contract should contain proper contractual arrangements which identify and allocate risks equitably, provide realistic obligations and clear objectives and targets, provide for formal dispute resolution processes, and also include motivation and incentives to the contracting parties.

\subsection{Good relationships}

The issue of the relationship between construction project participants has been a focus of attention in the literature since the early 1980s, with particular attention on the difficulty of achieving strong relationships between clients and contractors (Khan and Reinhart, 1990; Bresnen and Marshall, 2000). The interaction between project participants is often a key factor in project management. Interactive processes include planning, communication, monitoring and control, and project organization in order to facilitate effective coordination throughout the project life. It is essential that appropriate interpersonal skill are encouraged, and that a good working relationship between client, project team members and stakeholders is maintained. Inter-organizational conflicts in a construction project most often have adverse effect on project performance (Mohsini and Davidson, 1992). Good relationships are pre-requisite by timely payments on the part of the owner, fewer claims on the part of the contractor, and the absence of legal disputes.
5.6 Skill/Competence to each and all key project participants Projects are often managed by people who probably have to make decisions and enforce procedures that might affect other people. Project participants should possess adequate capability, including skill and experience. These skills and principles may include planning, optimizing, controlling, coordinating, motivating, communicating, procuring, and leading, delegating and negotiating (Fayol, 1949). Project management tends to apply these skills and techniques to the organization and control of all aspects of every project in order to optimize the use of resources to produce a welldesigned, soundly constructed, functional and financially viable facility that will satisfy the client's requirements of quality, purpose, safety, cost and time budget, and future maintenance (CIB, 2010).

\subsection{Information sharing to enable common understanding of project circumstances}

Information sharing is the process of exchanging information between two or more people (Ford and Staples 2010). This entails accurate, timely, frequent and two-way exchange of relevant information to build confidence and trust among project participants. Many of today's complex projects are developed by multidiscipline teams that are geographically distributed across several firms and even multiple continents (Geraldi et al., 2011). It is no surprise therefore that project participants are increasingly realizing that sharing information is key to project success (McDermott et al, 2005). The need for information sharing is emphasized due to the 'crossfunctional' or 'inter-organizational' nature of these projects (Nycyk, 2011). It is typical for these 'multidisciplinary' projects that the participants in the project team may have different backgrounds: education, working experience, organizational culture, and working procedures. It is, therefore, possible that they do not have 'a common language' (Koskinen et al., 2003). This may cause misunderstandings and affect the end results of the project. According to Baiden et al. (2006), project information should be available, open and accessible to all project team members as an input for efficient decision making and in order to create effective integrated project teams. The challenge is to ensure that the right information gets to the appropriate person at the right time (Baiden and Price, 2011). The lack of information or a response from project stakeholders becomes critical for progressing with project decisions (Jorgensen and Emmitt, 2009). The integrated project team should be an environment for openness, where shared information is essential for mutual respect and effective collaboration (SFC, 2003). The transparent flow of information through these distributed teams is critical for project collaboration and informed decision-making. It is also critical that the team's project data and multidiscipline models be shared on a regular basis for project coordination, design review, and analysis. In addition, the project data needs to be organized and accessible; secure yet available to the right people, in the right context.

\subsection{Knowledge sharing throughout the project cycle}

Construction projects have well defined tasks, schedules and goals, all associated with different degrees of complexity and uncertainty. Yet, because of the underlying structure they 
provide a fertile opportunity to share knowledge within projects, across projects, and over time. The construction industry is a knowledge-based industry (Egbu et al. 2004; Carrillo et al., 2004) because the execution of construction activities requires specialized expert knowledge and problemsolving knowhow (Anumba et al., 2005). Knowledge sharing helps firms to mitigate inter-connected risks (Dyer and Singh, 1998), while the knowledge base enables interpreting knowledge to create value (Trkman and McCormack, 2009). One typical problem in knowledge sharing is that knowledge is not understood in the right way by the receiver of the message (Burley, 2010). A project failure can be the result of capturing the appropriate knowledge at an inappropriate time of the project (Fuller at el, 2008). The combination of the two makes knowledge sharing a very difficult task for the construction industry, resulting in poor efficiency of the overall process. In this context knowledge sharing has been viewed as a enabling factor to promote innovation and collaboration in management of risk for the construction projects.

\subsection{No blame culture among participants}

Baiden et al. (2006) agreed that a 'no blame' culture is a key indicator of team collaboration practice in construction projects. It's been suggested that it's vital to have an equitable relationship and no blame culture as well as to encourage initiative to work towards the joint resolution of problems as this can influence team members to minimise their level of exposure to poor performance and. Dulaimi et al. (2002) contend the need for projects to have an environment where people are allowed to admit fault on the basis that fault was to be learned from, so that collective responsibility in decision making can be achieved for the best of the project and thence promote working together in a spirit of trust, cooperation and collaboration.) Outlined the importance of the creation of a 'no blame' culture as it could encourage project teams to work collaboratively integrate people who may otherwise feel exposed by their mistakes (SFC, 2003).

\subsection{Mutual understanding of goals, responsibilities and constraints of the project}

Successful collaboration in risk management requires all project participants to understand and be dedicated and strongly committed to achieving, maintaining and fulfilling project goals. According to Love et al. (1998), the formulation and collective agreement of project goals within a multidisciplinary team environment at an early stage can contribute to successful teamwork Effective risk management depends on correct and comprehensive understanding of the risks facing a project team. Forques and Koskela (2009) urge that in achieving collective decision making, it is expected that all team members have their "voice" heard and that all ideas are open to discussion.

\subsection{Flexibility}

Collaboration in management of risk requires flexibility of the project participants in order to accommodate various changes to projects caused by complexity, uncertainty and dynamic nature of these projects. Husby et al. (1999), defines project flexibility as "the capability to adjust the project to prospective consequences of uncertain circumstances within the context of the project". This could be achieved through "late locking" of project concepts, specifications and organization (Miller and Lessard, 2000); continuous step-by-step locking of the project using decision gates models (Eskerod and Östergren, 2000) and incremental decision making (Genus, 1997); or using contingency planning, where a set of base plans is defined, but also a set of alternative plans that can be activated if needed (Chapman and Ward, 1997). Flexibility allows project teams to collaboratively change the course of action to manage risks and uncertainty.

\subsection{Seamless operation}

The majority of the authors viewed seamless operation with no organisational defined boundaries as a vital indicator of team integration practice in which the boundaries between individuals are diminished and team members work collaboratively towards mutually beneficial outcomes for the project (Kajewski et al, 2003). The existence of professionally oriented boundaries within the project team has contributed to the main issue of impaired project team integration within construction projects (Moore and Dainty, 2001). The purpose of an integrated project team (IPT) is to bring together diverse groups of people and combine them into a seamless team for the pursuit of common goals (SFC, 2003; and Forques and Koskela, 2009) which is very important for risk management in complex projects.

\subsection{Proactive and joint problem solving}

Previous research has indicated that reactive problem solving can be a bottleneck to collaboration in management of risk due to poor time and cost effectiveness (Yu et al, 2007). The practice of proactive risk management improves an organization ability to manage the existing and emerging risks and helps adapt quickly to unwanted events or crisis. The defining characteristics of proactive risk management are risk mitigation and risk impact reduction. Mitigation may occur at the level of a specific risk and target the underlying immediate cause, or it may be achieved by intervention at the root cause level. Identification and correction of root causes has high value for the project participants because corrective measures can have far-reaching positive effects well beyond the scope of an individual project. Mitigation measures are best undertaken in the early stages of a project when the team still has the ability to intervene in time to effect project outcome.

\subsection{Fair distribution of responsibility}

For effective collaboration in management of risks in construction projects, it is important to appreciate principles of equity and fairness in distribution of responsibilities as fairly described in the contracts. The need for project participants to identify and understand all potential risks associated with a project cannot be over-emphasized. One critical factor to achieving successful implementation of construction project participants' collaboration is the optimal sharing of risks and distribution of responsibilities between these parties. The guiding principle often adopted in identifying and allocating responsibilities is that the party with the best financial and technical capabilities to manage a particular activity should be responsible for the risks associated with that activity and 
receive the associated rewards or losses (Ward and Chapman, 1991; Edwards, 1995; Flanagan and Norman, 1993).

\subsection{CONCLUSION}

This paper has shown that collaboration plays an important role in effective risk management. It has discussed how enabling factors may be a good starting point for increasing collaboration between project participants to improve project results. The paper has presented fourteen [14] factors advocated by reviewed literature as crucial to enabling collaboration in risk management. These are Trust, open communication, commitment, fairly drafted contract, good relationship, skills/competence, information sharing, knowledge sharing, no-blame culture, mutual understanding, flexibility, seamless operation; proactive problem solving and fair distribution of responsibility.

\section{REFERENCES}

[1] Adetola, A., Goulding, J., and Liyanage, C. “ Collaborative engagement approaches for delivering sustainable infrastructure projects in the AEC sector: A review." International Journal of Construction Supply Chain Management Vol. 1, No.1.pp. 1-24, 2011

[2] Akintoye, A., and Main, J. "Collaborative relationships in construction, the Uk contractors' perception, Engineering, Construction and Architectural Management, Vol. 14, No. 6, pp. 597- 617, 2007.

[3] Anumba, C.J., Egbu, C., Carrillo, P. Knowledge Management in Construction, Blackwell Publishing, 2005

[4] Ashkenas, (2012). Why teams don't collaborate. Forbes, Availabile: http://www.forbes.com/sites/ronashkenas/2012/03/21 why-team-dontcollaborate/. (Acessed on October, 2017)

[5] Baiden, B.K., Price, A.D.F. and Dainty, A.R.J. The extent of team integration within construction projects International Journal of Project Management, Vol. 24 Vol. 2, pp. 13 - 23, 2006

[6] Baiden, B.K., and Price, A.D.F. "The effect of integration on project delivery team effectiveness," International Journal of Project Management Vol. 29, No. 2, pp. 129- 136, 2011.

[7] Beasley, M. S., Clune, R., and Hermanson, D. R. Enterprise risk management: an empirical analysis of factors associated with the extent of implementation. Journal of accounting and public policy, Vol.24, No.6, pp.521-531, 2005.

[8] Bennett, J. and Jayes, S. Trusting the Team: The Best Practice Guide to Partnering In Construction, 1995.

[9] Bourne, L and Walker D.H.T, "Advancing Project Management in Learning Organizations" The Learning Organization, Vol. 11, No.3, pp. 226-243, 2004.

[10] Bresnen, M. and Marshall, N. "Building Partnerships: Case Studies of Client-Contractor Collaboration in the UK Construction Industry," Construction Management and Economics, Vol.18, No.7, pp. 819-832, 2000

[11] Burley, D. "Information Visualization as A Knowledge Integration Tool," Journal of Knowledge Management Practice, Vol.11, No.4, 2010 .

[12] Carrillo, P., Robinson, H., Al-Ghassani, A. and Anumba, C. "Knowledge Management in UK Constructions: Strategies, Resources and Barriers," Project Management Journal, Sylva: Apr 2004, Vol.35, No.1, pp.46, 2004

[13] Cattie, C and van Riper, K.. "Collaboration's role in new work environment," $\quad$ FCW, 2012 from htt://fcw.com/articles/2012/12/07/collaboration-in-agencyenvironments.aspx (Accessed on October, 2017)

[14] Chapman, C., and Ward, S. Project Risk Management: Process, Techniques and Insights, John Wiley and Sons, 1997

[15] Charted Institute of Building Code of practice of project management for construction and development $4^{\text {th }}$ Ed. UK Wiley-Blackwell, 2010
[16] Cheung, S., Ng, T., Wong, S. P., and Suen, H. Behavioural Aspects in Construction Partnering, International Journal of Project Management, Vol.21, No.5, pp. 333-343, 2003.

[17] Chua, D. K. H, Kog, Y.C, Loh, P. K. "Critical Success Factors for Different Project Objectives," Journal of Construction Engineering and Management, Vol. 123, No. 3, pp. 142-150, 1999

[18] Cicmil, S and Marshall, D. "Insights into collaboration at the project level: complexity, social interaction and procurement mechanisms," Building Research and Information, Vol. 33, No. 6, pp. 523 - 535, 2005.

[19] Dainty, A. R, Briscoe, G. H and Millet, S. J. "New perspectives on construction supply chain integration," Supply Chain Management: An international Journal," Vol. 6, No. 4, pp. 163 - 173, 2001.

[20] Davies, A.; Dodgson, M.; Gann, D. "Dynamic capabilities in complex projects": The case of London heathrow terminal 5. Project Management Journal, Vol. 47, pp. 26-46, 2016

[21] Dirks, K. T. "The effects of interpersonal trust on work group performance" Journal of Applied Psychology, Vol. 84, No3, pp.445, 1999.

[22] Dulaimi, M.F., Ling, F.Y.Y., Ofori, G. and De Silva, N. "Enhancing integration and innovation in construction," Building Research \& Information, Vol. 30, No.4, pp.237 - 247, 2002.

[23] Dyer, J., and Singh, H. The Relational View: Cooperative Strategy and Sources of Inter-organizational Competitive Advantage, 1998.

[24] Edward. C. Practical risk management in construction industry, engineering management series; London: Thomas Telford, 1995.

[25] Egan, J. Rethinking construction: report of the construction task force on the scope for improving the quality and efficiency of UK construction, Department of the Environment, Transport and the Region, London, 1998.

[26] Egbu, C., Hayles, C., Anumba, A., Ruika, K and Quintas, P. Getting started in Knowledge management: Concise Guidance for Construction Consultants and Contractors Partners in Innovation Project (CI 39/3/709) UK, 2004

[27] Engelbrecht, A. Managing the media, the role played by the media as a channel for project communication on public infrastructure projects, the project manager, Vol.4, pp. 26-33, 2010.

[28] Evbuomwana, N.F.O and Anumbab, C.J. "An integrated framework for concurrent life-cycle design and construction," Advances in Engineering Software, Vol.29, No.7-9, pp. 587-597, 1998

[29] Eskerod, P., Östergren K. "Why do Companies Standardize Projects Work?," Project Management, Vol. 6, No 1, 2000.

[30] Faulkner, David, and Mark De Rond, eds. Cooperative Strategy: Economic, Business, and Organizational Issues. New York: Oxford University Press, Inc, 2000

[31] Fayol, H. General Principles of Management classical organization theory, General and Industrial management London Pitman Publishing Limited, 1949.

[32] Flanagan, R., Norman, G., (1993), Risk management and construction, Oxford, Blackwell Scientific Publications

[33] Ford, D., and Staples, S. "Are full and partial knowledge sharing the same?" Journal of knowledge management Vol.14, pp. 394-409, 2010.

[34] Forgues, D. and Koskela, L. "The influence of a collaborative procurement approach using integrated design in construction on project team performance,". International Journal of Managing Projects in Business, Vol. 2, No.3, pp. 370 - 385, 2009.

[35] Fowler, J. J., and Horan, P. "Are Information Systems' Success and Failure Factors Related?" An Exploratory Study, Journal of Organizational and End User Computing, Vol. 19, No. 2, pp.1-22, 2007.

[36] Fuller, M. A., Valacich, J. S., \& George, J. F. Information systems project management: A process and team approach (1st ed.), Prentice Hall., 2008

[37] Geraldi, J.G., Maylor, H., and Williams, T. "Now, let's make it really complex (complicated): A systematic review of the complexities of projects," International Journal of Operations \& Production Management, Vol.31, No.9, pp.966-990, 2011.

[38] Genus, A. Managing large-scale technology and inter-organizational relations: the case of the Channel Tunnel, Research Policy, Vol. 26, No 2, pp 169-189, 1997 
[39] Guzzo, R Salas, E and Associate. Team effectiveness and decision making in organizations, San Francisco: Jossey-Bass. Pp. 414, 1995

[40] Husby, O., Kilde, H. S., Klakegg, O. J., Torp, O., Berntsen, S. R., Samset, K. "Uncertainty as Benefit, Managing Project Uncertainty: Possibility, Risk, Decision, Action, The Norwegian Centre for Project Management at the Norwegian University of Science and Technology, Trondheim, Norway. Report no. NTNU 99006, 1999.

[41] Ibrahim, C.K.I, Costello, S. B and Wilkinson, S. "Key Relationship Oriented Indicators of Team Integration in Construction Projects," International Journal of Innovation, Management and Technology, Vol. 2, No. 6, 201

[42] Jin, X. H. and Ling, F. Y. Y. "Constructing a Framework for Building Relationships and Trust in Project Organisations: Two Case Studies of Building Projects in China." Construction Management and Economics, pp. 685-696, 2005.

[43] Jorgensen, Bo. And Emmitt, S. "Investigating the integration of design and construction from a "lean" perspective," Construction Innovation Vol.9, No.2, pp.225-240, 2009

[44] Kajewski, S., Chen, E., Brewer, G., Gameson, R., Gajendran, T. Kolomy, R., Lenard, D., MacKee, J., Martins, R., Sher, W., McCabe, K and J. McCann,, Project Team Integration: Communication, Coordination and Decision Support. Part A: Scoping Studies. Technical Report2001-008-C-04, CRC-CI, Queensland University of Technology, 2003. [Online] Available: http://eprints.qut.edu.au/17874/1/17874.pdf. (Accessed on July, 2016)

[45] Kerzner, H. . Project Management - A systems Approach to Planning, Scheduling and Controlling, 5th edition, Van Nostrand Reinhold: New York, 1995

[46] Khan, M.S and Reinhart, C.M. "Private investment and economic growth in developing countries," World Development, Vol. 18, No.1 pp.19-27, 1949.

[47] Kleffner, A. E., Lee, R. B., and McGannon, B. The effect of corporate governance on the use of enterprise risk management: Evidence from Canada. Risk Management and Insurance Review, Vol.6, No. 1, pp. 537, 2003

[48] Klemetti, A. , Risk Management in construction Projects, Helsink University of Technology: Finland, 2006.

[49] Koskinen, K. U., Pihlanto, P. and Vanharanta, H. 'Tacit knowledge acquisition and sharing in a project work context,' International Journal of Project Management, Vol. 21: pp. 281- 290, 2003

[50] Krishnan, R., Martin, X., and Noorderhaven, N. G. "When does trust matter to alliance performance?" The Academy of Management Journal ARCHIVE, Vol.49, No.5, pp.894-917, 2006

[51] Lambert, D.M. and Cooper, M.C. Issues in supply chain management. Industrial Marketing Management, Vol.11. No.1, pp. 65-83, 2000.

[52] Lau, E., and Rowlinson, S. "The implications of trust in relationships in managing construction projects," International Journal of Managing Projects in Business, Vol.4, No.4, pp. 633-659, 2011. doi http://dx.doi.org/10.1108/17538371111164056. (Accessed on July, 2016)

[53] Latham, M. Constructing the team, Final report of the government/industry review of procurement and contractual arrangements in the United Kingdom construction industry, London, HMSO, Department of Environment, 2011

[54] Leverick, F. and Littler, D., Risks and Rewards of Collaboration. Manchester School of Management, UMIST, Manchester, 1993

[55] Lewis, J. D. and Weigert, A., Trust as a Social Reality. Social Forces pp. 967-85, 1985

[56] Leung, M.Y., Chong, A., Ng. S.T and Cheung, M.C.K.,. "Demystifying stakeholders' commitment and its impacts on construction projects,' Construction Management and Economics, Vol. 22 No.7, pp. 701-715, 2004. Business Source Premier, EBSCO Host, (Online); DOI: 10.1080/0144619042000300736. (Accessed: 21 October 2017)

[57] Love, P.E.D., Skitmore, R.M., and Earl, G. "Selecting a suitable procurement method for a building project," Construction Management and Economics, Vol.16, No.2, pp.221-233, 1998

[58] Love, P.E.D., Gunasekaran, A. and Li, H. "Concurrent engineering: a strategy for procuring construction projects," International Journal of Project Management, Vol. 16 No. 6, 375 - 383. 1998
[59] Mayer, R. C., Davis, J. H., and Schoorman, F. D. "An Integrative Model of Organizational Trust," The Academy of Management Review, Vol.20, No.3, pp.709-734, 1995 .

[60] McDermott, P., Khalfan, M. and Swan, W. "Trust in construction projects," Journal of Financial Management of Property and Construction, Vol.10, No1, 19-31, 2005

[61] Mei-Yung, L., Chong, A., Ng, S. T., and Cheung, M. C. K., "Demystifying stakeholders' commitment and its impacts on construction projects," Construction Management and Economics, Vol. 22, No.7, pp.701-715. 2004

[62] Miller, R., Lessard, D. The Strategic Management of Large Engineering Projects, Shaping institutions, Risks and Governance, Massachusetts Institute of Technology, USA, 2000.

[63] Mohsini, R.S and Davidson C.S. "Determinant of performance in the traditional building process," Construction Management economic Journal Vol.10, No.4, pp.343-359, 1992

[64] Moore, R.M. and Dainty, A.R.J. “ Integrated project teams performance in managing unexpected changes events," Team performance management, Vol.5, No.7, pp. 212- 222, 1999

[65] Moore, R.M. and Dainty, A.R.J, '”Intra-team boundaries as inhibitors of performance improvement in UK design and build projects: a call for change" Construction Management and Economics, Vol.19, 559 - 562, 2001

[66] Nycyk, M. "Knowledge Management Practices On Large-Scale Construction Projects in An Australian Company: An Ethnographic Study," Journal of Knowledge Management Practices, Vol.12, No.4 2011

[67] Ochieng, E.G and Price, A.D. "Framework for managing multicultura project teams," Engineering, Construction and Architectural Management, Vol.16, No 6, pp. 527-543, 2009

[68] Perry, M., and Sanderson, D. "Coordinating joint design work, Design Studies," Vol.19 No.3, pp. 273-288, 1998.

[69] Pritchard, C.. The Project Management Communication Toolkit Norwood, Artech House Inc, 2004

[70] Project Management Institute (PMI). A guide to the project management body of knowledge. 5th ed. Newtown Square, PA: Project Management Institute, 2013

[71] Rahman, M. M and Kumaraswamy, M. M, "Relational contracting and Team building: assessing potential contractual and no contractual incentives," Journal of Management in Engineering, Vol. 24, No. 1, pp. $48-63,2008$

[72] Rousseau, D., Sitkin, S., Burt, R. and Camerer, C. "Not so differen after all: a cross-discipline view of trust" Academy of Management Review, pp. 393-404, 1998.

[73] Sanchez- Cazorla, A., Alfalla Luque, R., and Irimia Dieguez, A.I., "Risk Identification in Megaprojects as a Crucial Phase of Risk Management," A Literature Review. Project Management Journal Vol 47, No.6, pp75-93, 2016

[74] Soetanto, R and Proverbs, D.G. "Modeling the satisfaction of contractors: the impact of client performance," Engineering, Construction and Architectural Management, Vol.9, No.5-6, pp. 453 465,2002

[75] Stiles, J. "Collaboration for competitive advantage: the changing world of alliances and partnerships," Long Range Planning, Vol.28 No.5, pp.8-9, 1995

[76] Strategic Forum for Construction (SFC). The integration toolkit guide: integrated project team. London: 2003. Strategic Forum for Construction, [Online]. Available: http://www.strategicforum.org.uk/sfctoolkit2/ipt_workbooks/00.ht $\mathrm{ml}$. (Accessed on January, 2016)

[77] Tarricone, P., Luca, J. "Employees, teamwork and socia interdependence- a formula for successful business," Team Performance Management, Vol. 8, No (3/4), pp.54-59, 2002 Available from: https://www.researchgate.net/publication/248345416 (accessed Nov 082017

[78] Trkman, P., and McCormack, K. Supply chain risk in turbulent environments - a conceptual model for managing supply chain network risk, 2009 
[79] Wards S.C and Chapman C.B., On the allocation of risk in construction projects, International Journal of Project Management Vol. 9, No. 3, pp.140-147, 1991

[80] Wiguna, P.A and Scott, S, Relating risk to project performance in Indonesian building contract, Construction management and Economics Vol. 24 No. 11, 2006

[81] Yaraghi, N., and Langhe, R.G. "Critical Success Factors for Risk Management Systems” Journal of Risk Research, Vol. 14, No. 5, pp. $551-581,2011$
[82] Yu, W. D., Lin, C. T., Yu, C.T., Liu, S.J., Luo, H. C and Chang, P.L.,(2007). Integrating emergent problem solving with construction knowledge management system, proceedings of the CME 25 Conference, July 16-18, 2007 University of Reading, Reading, UK, pp. 10

[83] Zaheer, A. and McEvily, B. Does Trust Matter? Exploring the Effects of Inter-organizational and Interpersonal Trust on Performance, Organization Science, pp. 141-159, 1998 